Jean-Pierre Chantin, Le régime concordataire français. La collaboration des Églises et de l'État (1802-1905)

Paris, Beauchesne, coll. « Bibliothèque Beauchesne ", 2010, 302 p.

Jean-Louis Schlegel

(2) OpenEdition

Journals

Édition électronique

URL : http://journals.openedition.org/assr/22968

DOI : $10.4000 /$ assr.22968

ISSN : $1777-5825$

Éditeur

Éditions de l'EHESS

Édition imprimée

Date de publication : 31 décembre 2011

Pagination : 140

ISBN : 9782713223273

ISSN : 0335-5985

Référence électronique

Jean-Louis Schlegel, « Jean-Pierre Chantin, Le régime concordataire français. La collaboration des Églises et de l'État (1802-1905) », Archives de sciences sociales des religions [En ligne], 156 | octobredécembre 2011, document 156-31, mis en ligne le 14 février 2012, consulté le 21 septembre 2020. URL : http://journals.openedition.org/assr/22968; DOI : https://doi.org/10.4000/assr.22968 


\section{Jean-Pierre Chantin, Le régime concordataire français. La collaboration des Églises et de l'État (1802-1905)}

Paris, Beauchesne, coll. «Bibliothèque Beauchesne ", 2010, 302 p.

Jean-Louis Schlegel

\section{RÉFÉRENCE}

Jean-Pierre Chantin, Le régime concordataire français. La collaboration des Églises et de l'État (1802-1905), Paris, Beauchesne, coll. «Bibliothèque Beauchesne », 2010, 302 p.

1 Le sous-titre de ce livre dit peut-être, dans une certaine mesure, le sens général de la formule concordataire, mais il n'en épuise pas les épisodes contrastés durant un siècle. La vue historique d'ensemble, assez détaillée, du régime concordataire que propose Jean-Pierre Chantin apporte en tout cas bien des nuances et des correctifs à l'idée d'une pratique uniforme et sans heurts majeurs d'une "convention", le mot initial pour désigner l'accord entre Bonaparte et le pape Pie VII. Si l'on retournait la célèbre formule de Clémenceau pour définir la laïcité, "L'État chez lui, l'Église chez elle », en faveur d'une définition du genre «l'État dans l'Église, et l'Église dans l'État » pour définir le Concordat, ce serait insuffisant, car la prééminence de l'État est nettement assurée. Il faut distinguer ici, comme pour la laïcité, la lettre et la mise en œuvre, ainsi que l'esprit de la mise en œuvre. L'un des grands intérêts de ce livre est en effet, après avoir bien situé les textes au départ, de montrer les différences successives d'interprétation, de par la volonté des régimes qui se suivent (presque toujours dans des ruptures violentes avec les précédents) ou du fait de situations critiques qui les obligent à changer leur politique de départ. C'est particulièrement net, mais en sens inversé, de Louis-Philippe et de Napoléon III. Ce que l'auteur fait aussi apparaître avec 
netteté, ce sont des niveaux d'opposition multiples qui fonctionnent tout au long de ce siècle de transition, chacun pour sa part, mais aussi en une sorte de tuilage permanent ou de dialectique multiple des intérêts: le cléricalisme très actif contre un anticléricalisme très décidé, l'un et/ou l'autre relayés par les gouvernements successifs ; une Église gallicane encore vivante, mais vivant ses ultimes soubresauts face à l'Église ultramontaine et aux prétentions de Rome ; les libéraux catholiques opposés aux intransigeants et finalement défaits, non sans responsabilités de leur part, après 1848, quand Montalembert rejoint le camp de la bourgeoisie catholique apeurée par la révolution sociale. Déjà faibles, les libéraux sont ainsi définitivement débordés à partir de Napoléon III par les intransigeants ultramontains, mais à partir de la Troisième République, les prétentions de ces derniers se paient cher à leur tour et sont politiquement réduites à néant par des coalitions de gauche, qui «feront » la laïcité d'autant plus facilement qu'elles seront réélues jusqu'à la Grande Guerre. « Facilement » veut dire ici qu'elles ne seront plus réellement freinées, mais bien sûr, comme chacun sait, ce furent des décennies d'opposition très forte entre droite et gauche, de durcissement des « deux France ».

2 On se souvient que c'est le pape Léon XIII qui finit par inviter les catholiques français à se rallier à la République. Cependant, déjà avant l'avènement des Républicains en 1876, on ne peut pas dire, me semble-t-il, que le Concordat fut une «loi de pacification " comme la loi de 1905. Il fut certes appliqué, mais aussi utilisé à des fins diverses, retouché selon les moments et surtout partiellement appliqué. Les épisodes peu glorieux de tous côtés, dictés par des intérêts divers, ne manquent pas. Juifs et protestants virent quelques améliorations de leur statut durant le siècle, mais ils n'y trouveront pas leur compte. Et un des problèmes est que, finalement, les catholiques eux-mêmes n'y trouvèrent pas leur compte : même si les politiques favorisèrent, ou durent favoriser, peu ou prou la religion de la «majorité des Français ", beaucoup continuèrent de rêver d'Ancien Régime. L'auteur note aussi le «trouble " permanent dû aux congrégations et à leur rôle dans l'enseignement - on pourrait ajouter : et aux fantasmes qu'elles suscitent. Il est frappant de constater qu'après la Révolution le gallicanisme semble avoir fait son temps, qu'il va succomber inexorablement face à l'État moderne "athée » et aux droits universels marqués par la Révolution, mais on reste toujours surpris, aussi, par les maigres raisons théologiques et les intérêts toujours très politiques de l'ultramontanisme, qui s'impose par KO, en 1870, sans avoir, semble-t-il, explicité pleinement ses raisons de porter la puissance spirituelle du pape au-delà de l'imaginable. Notons encore qu'à partir de l'année 1876, même chez bien des Républicains, l'idée de séparation totale de l'Église et de l'État n'allait pas de soi. Enfin, il reste cet épisode toujours un peu mystérieux de 1848, sorte d'étoile filante dans le ciel des relations entre religion et pouvoir, avec ses fraternisations et son utopie sociales. La suite, le renversement napoléonien, ses affinités avec les ultras puis l'appui donné contre toute raison à la sauvegarde des États pontificaux, étaient peut-être inscrits dans les embrassades illusoires de 48 : leur arrêt brutal aura des effets négatifs durables sur la perception de l'Église, et Victor Hugo, par exemple, ne s'en remettra jamais.

3 L'auteur a ajouté de nombreux encarts avec des textes et des cartes difficiles à trouver, ainsi qu'une annexe avec les textes du "Concordat ", les textes réglementant le culte israélite, le traitement des ministres du Culte, des textes sur l'administration 
des cultes, le texte de la loi de «Séparation » de 1905. On trouve aussi une chronologie, une bibliographie, un index des noms, une table des cartes et une table des encadrés. 